\title{
HYPERTROPIA FOLLOWING INSERTION OF INFERIORLY SITED DOUBLE-PLATE MOLTENO TUBES
}

\author{
N. WILSON-HOLT, W. FRANKS, B. NOURREDIN, R. HITCHINGS \\ London
}

\begin{abstract}
SUMMARY
The use of double-plate Molteno tubes is well established in the management of intractable glaucoma, particularly in eyes that may have had previous surgical procedures, often involving the superior conjunctiva with subsequent subconjunctival scarring. As it is frequently the case that the area of least scarring is inferiorly, we have sited the tubes there but have found that, although this usually provides good control of intraocular pressure, successful drainage of aqueous has been associated with the development of hypertropia due to upward displacement of the globe by fluid encapsulated around the plates. We report a retrospective study of $\mathbf{1 6}$ eyes undergoing inferiorly sited double-plate Molteno tubes, in which 9 eyes developed significant hypertropia at a mean time after insertion of $\mathbf{3 . 5}$ months. Mean degree of hypertropia was 9.8 prism dioptres. The management of this complication is discussed.
\end{abstract}

The use of Molteno tubes is well established in the management of intractable glaucoma, ${ }^{1 \times}$ typically in eyes that may have had previous surgical procedures, often involving the superior conjunctiva with consequent subconjunctival scarring. Recognised complications involving the conjunctiva include tube erosion through conjunctival suture lines, and failure of the tube to control intraocular pressure because of fibrosis around the plates interfering with aqueous drainage. ${ }^{5.6}$

In deciding where the plates should be placed, these factors are taken into consideration; and it is frequently the case that the area of least scarring is inferiorly. Doubleplate Molteno implants are used in preference in eyes at high risk of subconjunctival fibrosis to maximise the area for aqueous drainage," with the plates positioned on each side of the inferior rectus muscle. Although this usually provides good control of intraocular pressure, we have found that successful drainage has been associated with the development of hypertropia linked with restriction of downward movement and upward displacement of the globe by fluid accumulating around the plates and encapsulated by fibrous tissue.

Correspondence to: N. Wilson-Holt. FRCS, Moorfields Eye Hospital. City Road. London ECIV 2PD, UK.

\section{PATIENTS AND METHODS}

The indications for surgery were those eyes in which the intraocular pressure was greater than $24 \mathrm{mmHg}$ on maximally tolerated medical therapy, in patients who had had previous surgery involving the superior conjunctiva so that previous trabeculectomies had failed, or were at high risk of failure due to subconjunctival fibrosis. In all cases there was evidence of progressive glaucomatous optic disc damage.

Retrospective study of the patients' records included details of age, sex, history of strabismus, and history of previous ocular or extraocular surgery. A full ophthalmic examination had been performed in each case, including visual acuity and anatomical status of the fellow eye. No patient had any history or findings of strabismus prior to tube insertion.

\section{Surgical Technique}

A limbal conjunctival peritomy of $180^{\circ}$ was made, and the inferior rectus muscle secured. After thorough cleaning of the sclera the double-plate Molteno tube was inserted, straddling the inferior rectus with the connecting tube lying beneath the muscle belly approximately $9 \mathrm{~mm}$ from the limbus, and applied to the sclera by two 8.0 nylon sutures to each plate (Fig. 1). Care was taken to avoid any trauma to the inferior oblique muscle. A thick partialthickness scleral flap $(6 \mathrm{~mm} \times 8 \mathrm{~mm})$ was dissected, and the anterior chamber end of the tube shortened to create an oblique opening to the tube. In all cases a 6.0 vicryl suture was tied firmly around the posterior end of the tube, close to its attachment to the plates, and the non-patency of the tube/plate system confirmed. This manoeuvre was designed to prevent excessive drainage in the immediate postoperative period leading to hypotony. The tube was passed into the eye through an incision made with a posteriorly directed 27 gauge needle, and the scleral flap securely sutured with interrupted 8.() nylon to cover the tube. The conjunctiva was repositioned with 10.0 nylon, and in some cases the anterior chamber refilled, with balanced salt solution, a viscoelastic substance or, if the 


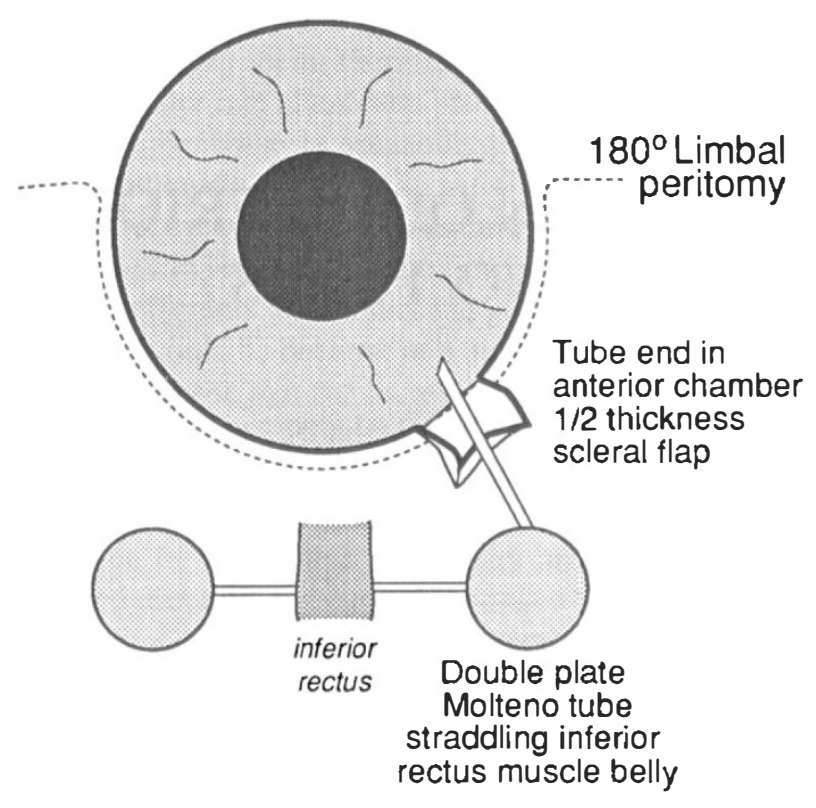

Fig. 1. Surgical technique for inferior placement of doubleplate Molteno implant, showing the two plates connected by a silicone rubber tube beneath the inferior rectus muscle. The site of entry into the eye is inferolateral.

eye was aphakic and/or vitrectomised, with a long-lasting non-expansile gas (e.g. $20 \% \mathrm{C}_{3} \mathrm{~F}_{8}$ ). Postoperatively the eyes were treated with topical chloramphenicol and dexamethasone. In the immediate postoperative period, if the intraocular pressure was inadequately controlled, medical therapy was used as necessary, preference being given to the use of a topical beta-adrenoceptor blocker, with or without the addition of a carbonic anhydrase inhibitor or other medications.

\section{Postoperative Assessment}

An initial examination was performed the day following surgery. Further examinations were performed 2-3 weeks after operation, or more frequently when clinically necessary and at 2-3 months. A final ocular and orthoptic assessment was performed at a mean postoperative duration of 9.8 months (range 5-18 months). Patients were assessed at the 2-3 month and final examinations with regard to (1) refraction, (2) measurement of Snellen visual acuity, (3) intraocular pressure, (4) presence or absence of diplopia, (5) near and distance deviations in primary and secondary positions of gaze using a prism and cover test or Krimsky testing when fixation was not possible, and (6) Hess chart assessment, when possible.

\section{RESULTS}

We studied 16 eyes in 16 patients who, over a 12 month period, underwent insertion of double-plate Molteno tubes, with the tube sited inferiorly. Mean patient age was 42.7 years (range 12-72 years). Mean preoperative intraocular pressure on maximal medical therapy was $44 \mathrm{mmHg}$ (range $30-62 \mathrm{mmHg}$ ). Nine patients were male, and 7 female.

At the time of intermediate examination, 9 of the 16 eyes had developed significant hypertropia of the operated eye (Table I), apparently due to the development of large cysts around each of the inferior plates, and restriction of downward movement of the globe. In all 9 patients the hypertropia was present in the primary position; 1 patient demonstrated a hyperphoria, and the remainder were orthophoric. Of the hypertropic eyes, the mean angle of deviation was 8.8 prism dioptres (range 4-12 prism dioptres), and prism cover testing showed that the angle of deviation was the same in all positions of downward gaze

Table I. Hypertropic eyes: patient data

\begin{tabular}{|c|c|c|c|c|c|c|c|c|c|c|}
\hline \multicolumn{3}{|c|}{$\begin{array}{l}\text { Patient } \\
\text { details }\end{array}$} & \multirow{2}{*}{$\begin{array}{l}\text { Type of } \\
\text { glaucoma }\end{array}$} & \multirow{2}{*}{$\begin{array}{l}\text { Previous } \\
\text { operations }\end{array}$} & \multirow{2}{*}{$\begin{array}{l}\text { Pre-op } \\
\text { IOP } \\
(\mathrm{mmHg})\end{array}$} & \multirow{2}{*}{$\begin{array}{l}\text { Time of onset } \\
\text { of diplopia/ } \\
\text { hypertropia } \\
\text { after tube } \\
\text { surgery } \\
\text { (months) }\end{array}$} & \multirow{2}{*}{$\begin{array}{l}\text { Degree of } \\
\text { hypertropia } \\
\text { at final } \\
\text { follow-up }\end{array}$} & \multicolumn{2}{|c|}{ Follow-up } & \multirow{2}{*}{$\begin{array}{l}\text { Visual } \\
\text { acuity }\end{array}$} \\
\hline No. & Age & Sex & & & & & & $\begin{array}{l}\text { Duration } \\
\text { (months) }\end{array}$ & $(\mathrm{mmHg})$ & \\
\hline 1 & 27 & $\mathbf{M}$ & $\begin{array}{l}\text { Heterochromic } \\
\text { cyclitis }\end{array}$ & $\begin{array}{l}\text { ECLE, } \\
\text { trabeculectomy }\end{array}$ & 50 & 2 & $10 \Delta$ & 12 & 28 & $6 / 18$ \\
\hline 2 & 53 & $\mathbf{M}$ & ICE syndrome & $\begin{array}{l}\text { Trabeculectomy } \\
(\times 2)\end{array}$ & 30 & 2 & $2 \Delta$ & 13 & 22 & $6 / 18$ \\
\hline 3 & 44 & $\mathbf{M}$ & Penetrating trauma & $\begin{array}{l}\text { Vitreo-lensectomy, } \\
\text { trabeculectomy }\end{array}$ & 42 & 1 & $6 \Delta$ & 18 & 14 & $\mathrm{CF}$ \\
\hline 4 & 54 & $\mathbf{M}$ & $\begin{array}{l}\text { Pseudophakic } \\
\text { glaucoma }\end{array}$ & Cyclodialysis & 35 & 3 & $10 \Delta$ & 7 & 22 & $6 / 60$ \\
\hline 5 & 14 & $\mathrm{~F}$ & $\begin{array}{l}\text { Congenital } \\
\text { cataracts }\end{array}$ & $\begin{array}{l}\text { Multiple needlings } \\
\text { in infancy }\end{array}$ & 45 & 1 & $10 \Delta$ & 5 & 20 & $6 / 24$ \\
\hline 6 & 36 & $\mathbf{M}$ & ICE syndrome & $\begin{array}{l}\text { Trabeculectomy } \\
(\times 2)\end{array}$ & 34 & 4 & $7 \Delta$ & 7 & 23 & $6 / 9$ \\
\hline 7 & 50 & $\mathbf{M}$ & Penetrating trauma & $\begin{array}{l}\text { Penetrating } \\
\text { keratoplsty }(\times 2) \text {, } \\
\text { ICLE trabeculectomy }\end{array}$ & 53 & 2 & $15 \Delta$ & 13 & 16 & $3 / 18$ \\
\hline 8 & 59 & $\mathrm{~F}$ & $\begin{array}{l}\text { Chronic angle } \\
\text { closure/malignant } \\
\text { glaucoma }\end{array}$ & $\begin{array}{l}\text { Trabeculectomy, } \\
\text { ECLE/IOL/ } \\
\text { cyclodialysis }\end{array}$ & 48 & 3 & $10 \Delta$ & 7 & 22 & $6 / 12$ \\
\hline 9 & 65 & $\mathrm{~F}$ & $\begin{array}{l}\text { Herpes zoster } \\
\text { pseudophakia }\end{array}$ & $\begin{array}{l}\text { Trabeculectomy, } \\
\text { ECLE+IOL }\end{array}$ & 62 & 1.5 & $10 \Delta$ & 4 & 29 & $6 / 24$ \\
\hline
\end{tabular}

${ }^{a}$ ECLE, extracapsular cataract extraction; ICLE, intracapsular cataract extraction; IOL, intraocular lens. 


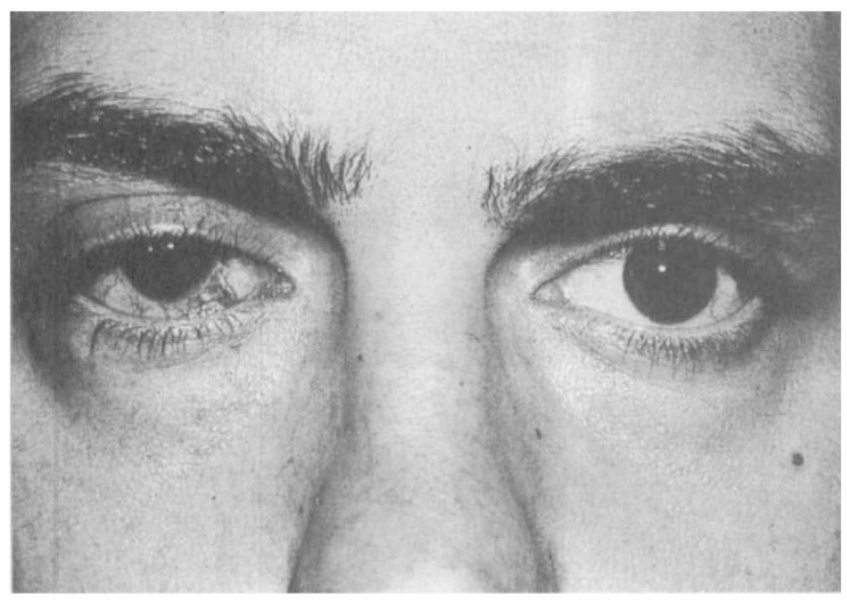

Fig. 2. Case 1, demonstrating hypertropia of the right eye in the primary position 4 months after inferior placement of a double-plate Molteno tube. There are tense cysts around each of the plates straddling the inferior rectus belly, displacing the eye superiorly.

for both distance and near vision. Vertical diplopia (worse on downward gaze) was experienced by 5 patients with hypertropia, and in 3 cases could be satisfactorily managed with Fresnel prisms.

At the time of final follow-up no new cases of hypertropia were detected. One patient demonstrated a spontaneous improvement in that both the symptom of diplopia and the measured angle of deviation had reduced by the final follow-up examination. Two patients underwent surgical exploration of the plates; traction tests performed at the time of this surgery showed restriction of depression of the globe. Surgery involved deroofing and marsupialisation of the subconjunctival component of the cystic area which was recovered with conjunctiva. This procedure was followed by a course of subconjunctival injec-

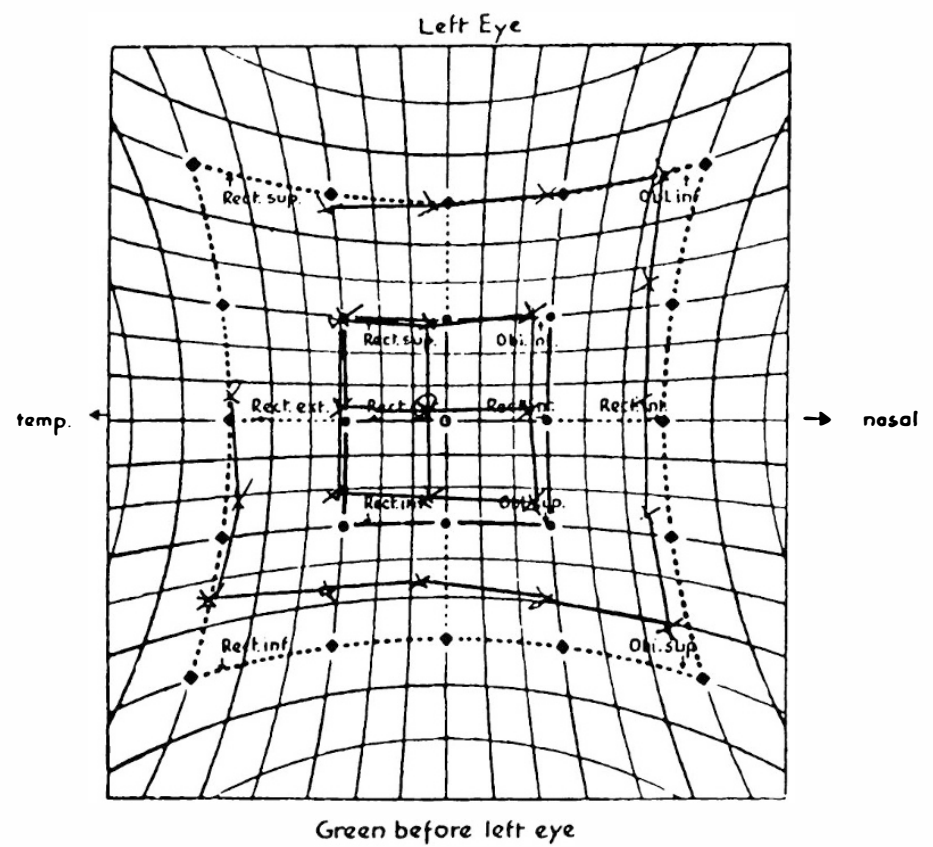

tions of 5-fluorouracil ( $5 \mathrm{mg}$ daily for 1 week followed by injections on alternate days for a second week) to try to limit further fibrosis. In both patients this procedure led to a reduction rather than elimination of the hypertropia. In the eyes with hypertropia, intraocular pressure was controlled without additional medical therapy $(23 \mathrm{mmHg}$ or below) in 7 cases, and required additional therapy in 2 cases. Five of 7 eyes without hypertropia had satisfactory intraocular pressure control without additional treatment, but 2 required a topical beta-blocker plus oral acetazolamide.

\section{CASE REPORTS}

\section{Case 1}

In November 1989 a 27-year-old man with glaucoma in the right eye secondary to heterochromic cyclitis underwent a double-plate Molteno tube procedure with the tube inserted inferonasally. Six months previously he had had a right extracapsular cataract extraction combined with trabeculectomy, but the intraocular pressure remained poorly controlled in spite of additional medical therapy.

Two months after tube insertion there was a moderate right hypertropia (6 prism dioptres) associated with large cysts around each of the inferior plates; at this stage the intraocular pressure was well controlled and visual acuity was $6 / 12$. However, by 4 months postoperatively the intraocular pressure had become elevated, necessitating a topical beta-blocker and acetazolamide, and the hypertropia was more marked (10 prism dioptres) (Fig. 2). A traction test revealed marked limitation of depression of the globe. Surgical exploration of the plates was therefore recommended, with marsupialisation of tenons cysts, followed by a course of subconjunctival 5-fluorouracil. After a short-lived improvement, intraocular pressure control

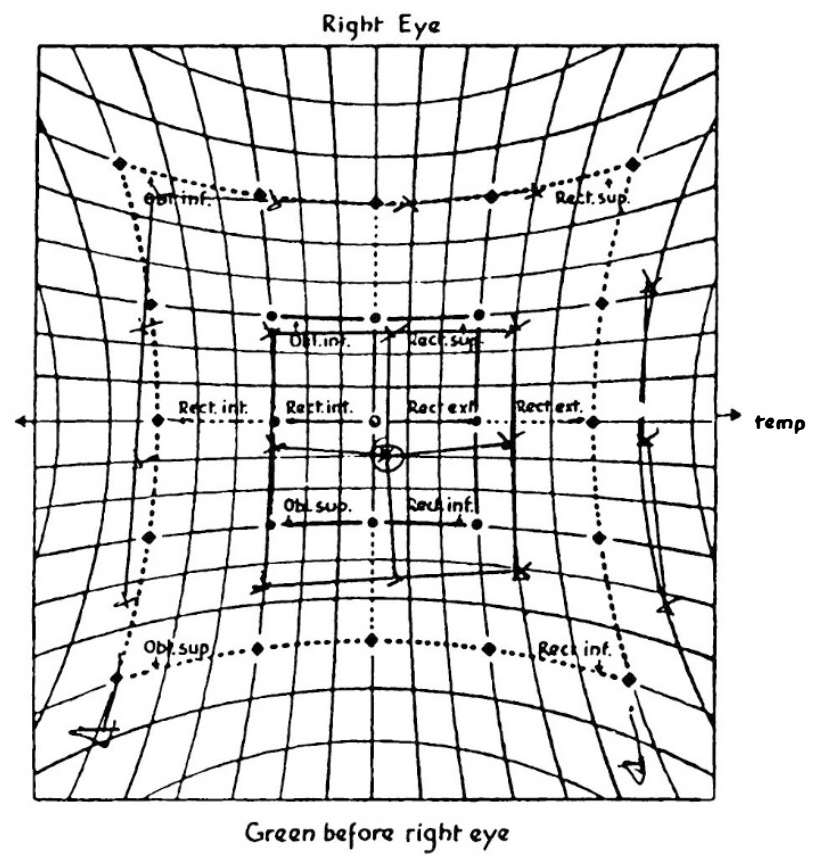

Fig. 3. Hess chart of case 2 at 3 months following inferior placement of a double-plate Molteno tube into the left eye. The chart is suggestive of mechanical restriction in the field of action of the left inferior rectus muscle. 

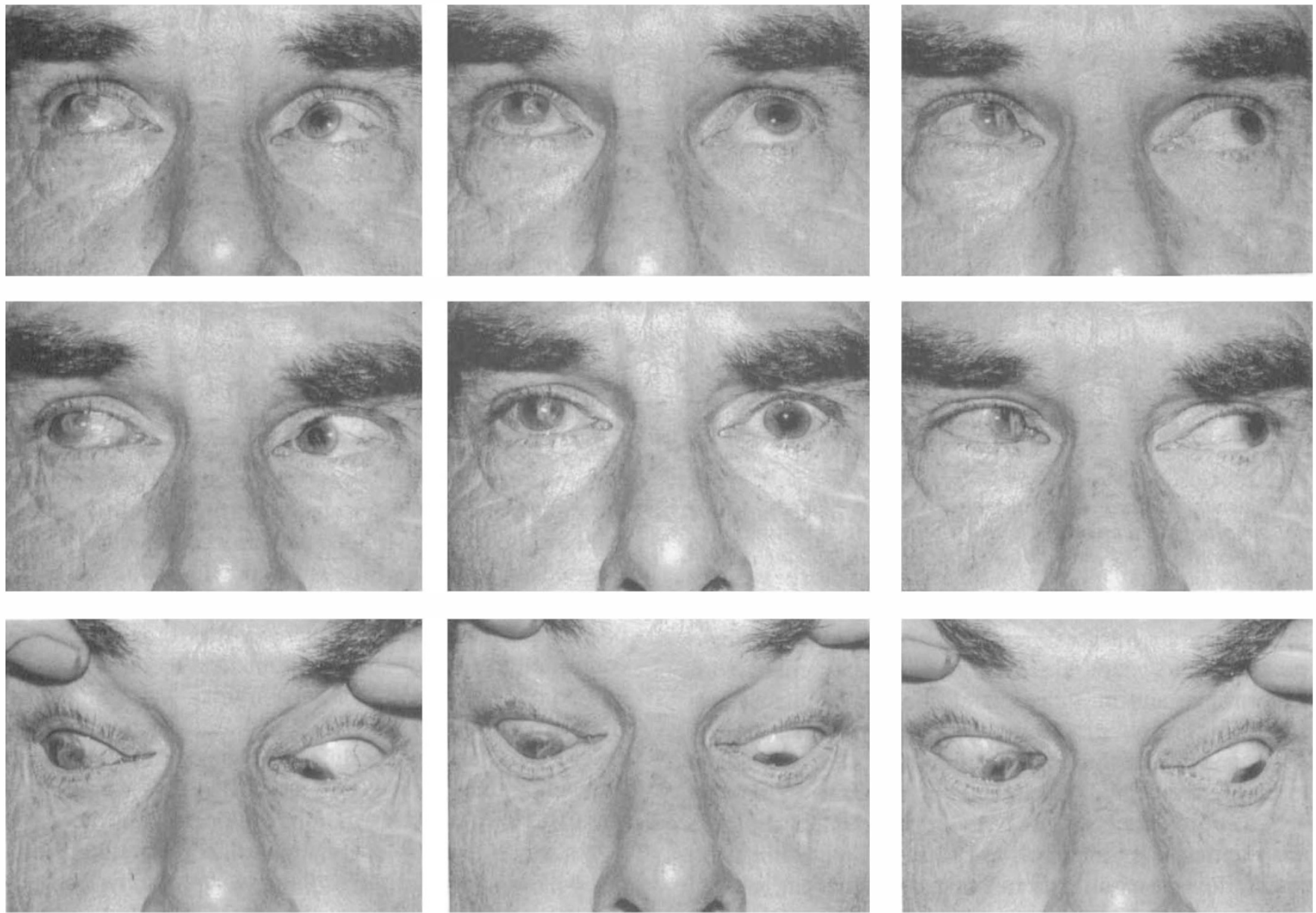

Fig. 4. Nine positions of gaze of patient in case 3 showing hypertropia of the right eye maximal in depressed positions of gaze.

deteriorated and the hypertropia again became marked ( 10 prism dioptres). At 8 months after the tube insertion, surgical removal of the tube was performed. This reduced the hypertropia, but the raised intraocular pressure had been difficult to treat, requiring repeated YAG laser cycloablations.

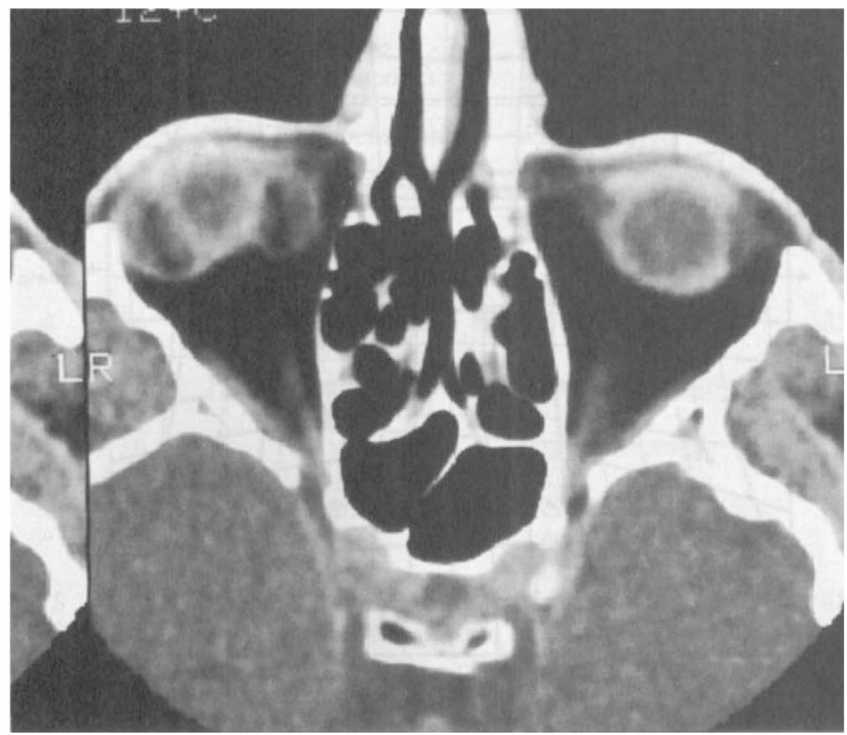

Fig. 5a.

\section{Case 2}

A 53-year-old man with iridocorneoendothelial syndrome affecting the left eye had a double-plate Molteno tube procedure becasue of uncontrolled intraocular pressure following two previous unsuccessful trabeculectomies. The tube was sited inferotemporally.

Two months after this procedure he developed vertical diplopia and was found to have a left hypertropia in the primary position (5 prism dioptres) with the vertical devia-

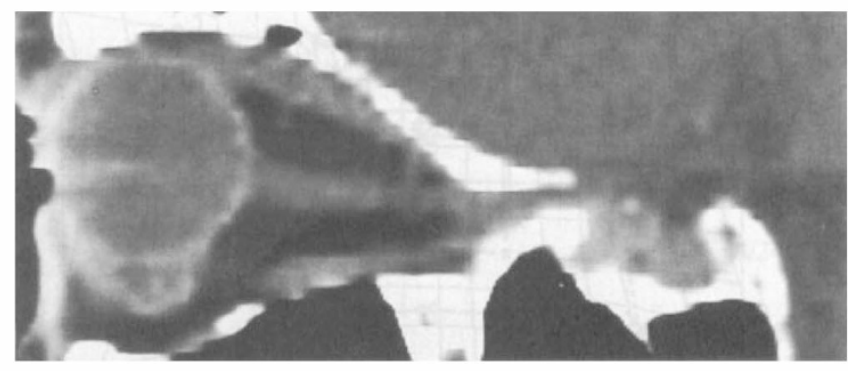

Fig. 5b.

Fig. 5. Coronal CT scan of the orbits (a) of case 3 at 5 months after inferior siting of a double-plate Molteno tube. There are cystic structures related to the inferior aspect of the right eye, both medially and laterally, corresponding to tense tenons cysts around the plates, causing proptosis; upward displacement of the globe is seen in the sagittal CT scan (b). 
tion most marked in positions of downward gaze; visual acuity in the left eye was $6 / 12$. The Hess chart is shown in Fig. 3. There were tense subconjunctival cysts present around each of the plates, with the intraocular pressure elevated at $40 \mathrm{mmHg}$. The diplopia was satisfactorily managed by the use of a Fresnel prism. Both the ocular deviation and intraocular pressure have subsequently reduced over a period of 13 months follow-up after tube insertion.

\section{Case 3}

A 44-year-old man developed secondary glaucoma following penetrating trauma of his right eye. In January 1988 a trabeculectomy was performed, but the intraocular pressure thereafter became uncontrolled and in June 1989 a double-plate Molteno tube was inserted with the tube sited inferotemporally.

Hypertropia of the right eye (Fig. 4), maximal in depressed positions of gaze (10 prism dioptres), developed after lysis of the 6.0 vicryl tie, and was associated with large cystic blebs around both of the plates. Highresolution computed tomographic scans of the orbit were obtained which confirmed the diagnosis (Fig. 5), and 5 months after the tube insertion the plates were explored and the cystic blebs around the plates deroofed. Traction testing at the time of surgery showed marked limitation of depression. Following surgical exploration there was a small but definite improvement in the hypertropia (6 prism dioptres), the intraocular pressure remaining controlled (14 $\mathrm{mmHg}$ ) at 18 months follow-up.

\section{DISCUSSION}

Vertical muscle imbalance is well recognised following insertion of surgical explants, typically in retinal detachment surgery. ${ }^{9-16}$ Postulated mechanisms for strabismus following buckling procedures include adhesions causing muscle restriction, a bulk effect of the buckle beneath an extraocular muscle, and direct muscle injury. In the series of eyes having inferiorly sited Molteno tubes reported here the cause of the muscle imbalance is superior displacement of the globe by tense subconjunctival cysts around the plates, and a limitation of depression of the globe by the bulk effect of the cysts. This complication is not seen in eyes having superiorly placed tubes because of the greater capacity of the orbital roof to accommodate peribleb cysts.

Although intraocular pressure control may not be compromised in such eyes, elevation of the globe by cysts around the plates causes diplopia, and can be cosmetically unsightly. Management of this complication should be aimed at reducing the degree of fibrosis around the plates and includes medical and surgical treatment.

The role of adjunctive anti-inflammatory therapy, particularly systemic steroids, in controlling postoperative fibrosis to improve the success rate of Molteno implant surgery is controversial, ${ }^{3.5 .9}$ and we used only intensive topical steroids. However, although we believe that the use of adjuvant subconjunctival 5-fluorouracil injections might more effectively control postoperative fibrosis, both of the cases in which we used 5-fluorouracil required reoperation. Tissue plasminogen activator might be of benefit by limiting, at an early stage, the laying down of fibrin around the plates thereby preventing the formation of a scaffold upon which a fibrous capsule is later built. However, recent reports show a very short-lived effect of this agent, which may limit its use in practice. ${ }^{17.18}$

Surgical treatment involving dissecting out and deroofing the thickened tenons cysts was undertaken in 2 cases. In both cases this reduced rather than eliminated the hypertropia. Although surgical intervention did not adversely affect intraocular pressure control in case 3 , this did occur in case 2 and, unless essential, we advise against reoperation as this may cause further fibrosis thereby compromising aqueous drainage.

Management with prisms may be difficult because the angle of vertical squint may be large. Unlike retinal detachment surgery where explants may be removed without significant ocular morbidity, ${ }^{15}$ this does not apply in drainage tube implants.

In this series 9 of 16 eyes with inferiorly placed Molteno tubes developed significant ocular displacementwhich proved difficult to treat. Siting the implant inferiorly may be technically simpler and in theory gives better results than superior placement in eyes with extensive conjunctival scarring superiorly. However, we feel that inferior placement should be avoided if postoperative diplopia could occur.

We thank Mr. J. P. Lee, FRCS, FCOphth, for helpful advice with the preparation of this paper.

Key words: Diplopia, Glaucoma, Hypertropia, Molteno tube.

\section{REFERENCES}

1. Ancker E, Molteno ACB: Molteno drainage implant for neovascular glaucoma. Trans Ophthalmol Soc UK 1982, 102: $122-4$.

2. Brown RD, Cairns JE: Experience with the Molteno long tube implant. Trans Ophthalmol Soc UK 1983, 103: 299-312.

3. Freedman J: Scleral patch grafts with Molteno setons. Ophthalmic Surg 1987, 18: 532-4.

4. Heuer DK, Abrabs DA, Baarvelot G, et al: Randomized clinical trial of single and double plate Molteno implants in patients with poor clinical prognosis. Invest Ophthalmol Vis S(i 1989, 30 (Suppl): 282.

5. Minckler DS, Heuer DK, Hasty B, et al: Clinical experience with the Molteno implant in complicated glaucomas. Ophthalmology 1988, 95: 1180-8.

6. Molteno ACB: Use of Molteno implants to treat secondary glaucoma. In: Cairns JE, editor. Glaucoma, vol 1. London: Grune and Stratton, 1986, pp. 211-38.

7. Traverso CE, Tomey FK, Al-Kaff A, et al: The Molteno draining implant for the management of complicated glaucoma cases. Ophthalmology 1987, 94 (Suppl): 80.

8. Melamed S and Fiore PM: Molteno implant surgery in refractory glaucoma. Surv Ophthalmol 1990, 34: 441-8.

9. Molteno ACB: The optimal design of drainage implants for glaucoma. Trans Ophthalmol Soc NZ 1981, 33: 39-41.

10. Mets MB, Wendell ME. Gieser RG: Ocular deviation after retinal detachment surgery. Am .J Ophthalmol 1985, 99: $667-72$. 
11. Arruga A: Motility disturbances induced by operations for retinal detachment. Mod Prob Ophthalmol 1977, 18: 404-14.

12. Kanski JJ, Elkington AR, Davies MS: Diplopia after retinal detachment surgery. Am J Ophthalmol 1973, 76: 38-40.

13. Sewell JJ, Knoblock WH, Eifrig DE: Extraocular muscle imbalance after surgical treatment for retinal detachment. Am J Ophthalmol 1974, 78: 321-3.

14. Wolff SM: Strabismus after retinal detachment surgery. Trans Am Ophthalmol Soc 1983, 81: 182-92.

15. Munoz M, Rosenbaum AL: Long-term strabismus compli- cations following retinal detachment surgery. J Pediatr Ophthalmol Strabismus 1987, 24: 309-14.

16. Smiddy WE, Loupe D, Michels RG, et al: Extraocular muscle imbalance after scleral buckling surgery. Ophthalmology 1989, 96: 1485-9.

17. Sternberg P, Aguilar H, Drews C, Aaberg TM: The effect of tissue plasminogen activator on retinal bleeding. Arch Ophthalmol 1990, 108: 720-2.

18. Williams GA, Lambrou FH, Jaffe GA, et al: Treatment of postvitrectomy fibrin formation with intraocular tissue plasminogen activator. Arch Ophthalmol 1988, 106: 1055-8. 